\title{
Application flasks for the barrier layer device in reinforced concrete structures
}

\author{
Yuliya Kozhevnikova ${ }^{1, *}$, and Olga Razinkova ${ }^{1}$ \\ ${ }^{1}$ Astrakhan State University of Architecture and Civil Engineering, Civil building department, \\ 414056, 18 Tatishcheva str., Astrakhan, Russia
}

\begin{abstract}
Determination of the optimal composition of solutions for use in the barrier layer for buried and semi-buried reinforced concrete structures.
\end{abstract}

\section{Introduction}

Modern conditions for the development of urban areas cannot be imagined without the development of underground space for temporary parking, garages, road junctions, etc.

Prospects for the development of cities are possible due to the expansion of urban areas, while the central areas of the city, including its historical centers, have practically exhausted their potential.

Moving transport interchanges and urban infrastructure under the ground could solve many problems of city development. However, this requires new engineering solutions.

The Astrakhan region is distinguished by particularly difficult geological and hydrological conditions, one of which is a high degree of salinity of the base soil. Saline soils containing large amounts of readily soluble salts are extremely aggressive towards the concrete. The processes of corrosion of materials in saline soils, due to the deposition of salts in the pores of the concrete, their transition to crystalline forms with an increase in the volume of solid phases, belong to the third type of corrosion.

Concrete - it is a structure penetrated by pores, capillaries, and micro-cracks if it is prepared according to standard technology. The formation of this structure is due to several reasons: insufficient concrete compaction during pouring; evaporation of water during the setting of concrete; internal stress arising due to shrinkage of concrete during the setting process, etc. $[1,2]$. As a result, mineralized groundwater penetrates the open pores and capillaries of materials in contact with them.

In the arid phase, the salt solution concentration increases to a saturated state and salts crystallize, which is accompanied by pressure on the walls of pores and capillaries, an increase in stresses that cause deformation and destruction of the material.

A set of measures is being taken to combat salt corrosion, including full or partial waterproofing of foundations, insulation of walls and socles, and the installation of waterproof substrates.

\footnotetext{
*Corresponding author: cad@aucu.ru
} 
Work on the installation of various types of waterproofing is imperfect, includes a significant amount of manual labor and depends on the quality of preliminary preparation of the treated surface.

In this regard, the aim of the work is to obtain a composite composition for use as a waterproof barrier layer operating at the media boundary, which is performed at a low cost, using the "screen technology" method in concrete and reinforced concrete buried and semiburied structures, in which such an indicator as water permeability.

\section{Methods}

Here is what was done in the process:

1. Using a device to create a "barrier layer" on individual structures on the construction site.

2. Obtaining stable, with a given error, characteristics of structures and materials manufactured in the field.

3. Organization of the process of operational quality control of a two-layer composite at construction sites.

4. Development of technological regulations for the construction of structures using screen technology in a construction site.

Given that fierce competition in the construction, the market requires the implementation and planning of construction and installation work, from construction organizations at a high level, and the introduction of new technologies, the more complex the process, because it is associated with certain financial risks.

Pilot testing of the developed compositions and methods for constructing the barrier layer with additives from local mineral raw materials was carried out on reinforced concrete structures of technological pits at the following facilities:

1. The building of a 2-story hotel with 60 beds in the recreation center "Lotus";

2. Office building LLC "S.M.A. Troya", Astrakhan.

Techniques for waterproofing coatings, silicification, cementation, etc. surfaces in contact with the external environment are used in construction. Also, new materials are known that are used as special additives in concrete mixes.

Penetron additives and its derivatives are widely used in the construction market.

The technology for waterproofing, cementing and silicate has several disadvantages:

- Need for thorough preliminary surface preparation;

- Providing an insulating adhesive layer with a surface structure;

- A large amount of manual labor;

In the case of using "Penetron" type additives, the technological regulations for the material involve:

- Dosed introduction of various additives into the concrete mixture at the stage of its manufacture with averaging during mixing;

- Applying compositions manually on a pre-prepared surface;

- Compliance with the conditions for subsequent care of concrete in the process of curing.

Both in the first and in the second case, an additional "refinement" of the structure leads to a significant increase in its cost.

Theoretical concepts of the diffusion of salts through solid surfaces and materials with different porosity, density, humidity, and temperature require the development of new materials, means, and methods of protecting structures from the negative (destructive) effects of diffusion products on the structure of the material. 
The properties of concrete compositions with partial use of local raw materials were studied, and the improvement of buried and semi-buried structures using the "screen technology" method was proposed.

Screen technology involves the installation of a barrier layer in building structures and includes a volumetric rectangular standard form 1 , in which the insert sheet 2 is fixed by installing three pair of movable clips 4 on the end faces of form 6 . Over the entire surface of the insert-diaphragm, 2 is perforated with holes 3 , with a diameter of not more than 5 $\mathrm{mm}$, taking into account the particle size distribution of the fine aggregate, the pitch of the perforation holes is not more than $100 \mathrm{~mm}$. At the top of the insert sheet 2, there are mounting loops 5 (рис. 1).

Device for creating a barrier layer in building structures works as follows:

- prepared for concreting form 1 is filled with the concrete mixture in the main volume;

- The specially prepared mixture is fed into compartment 7 separated by the insert 2 ;

- Liner 2 (Fig. 2) is removed at the end of the concreting process, taking into account the laboratory-defined setting start time for the mixtures used, or after a slight vibration load, since the use of self-compacting mixtures is characterized by the ability to stack them without vibration, under the action of their own weight;

- cleaning the liner 2 with perforation with holes 3 after removal from the body of the structure is carried out by immersing it in a bath with water.

Use of hard mixes with water-cement ratio $(\mathrm{WCR})=0,4(0,45)$ involves the use of additional vibration load. For this, a second liner has been developed (Fig. 4 and 5).

The proposed device for creating a barrier layer in building structures provides:

- protection of structures from the negative (destructive) effects of diffusion products on the structure of the material;

- reducing the complexity during installation;

- simplicity in operation;

- protection of the surface of the structure that is in direct contact with the aggressive environment.

Given all these advantages, the proposed device can be widely used in construction practice. 


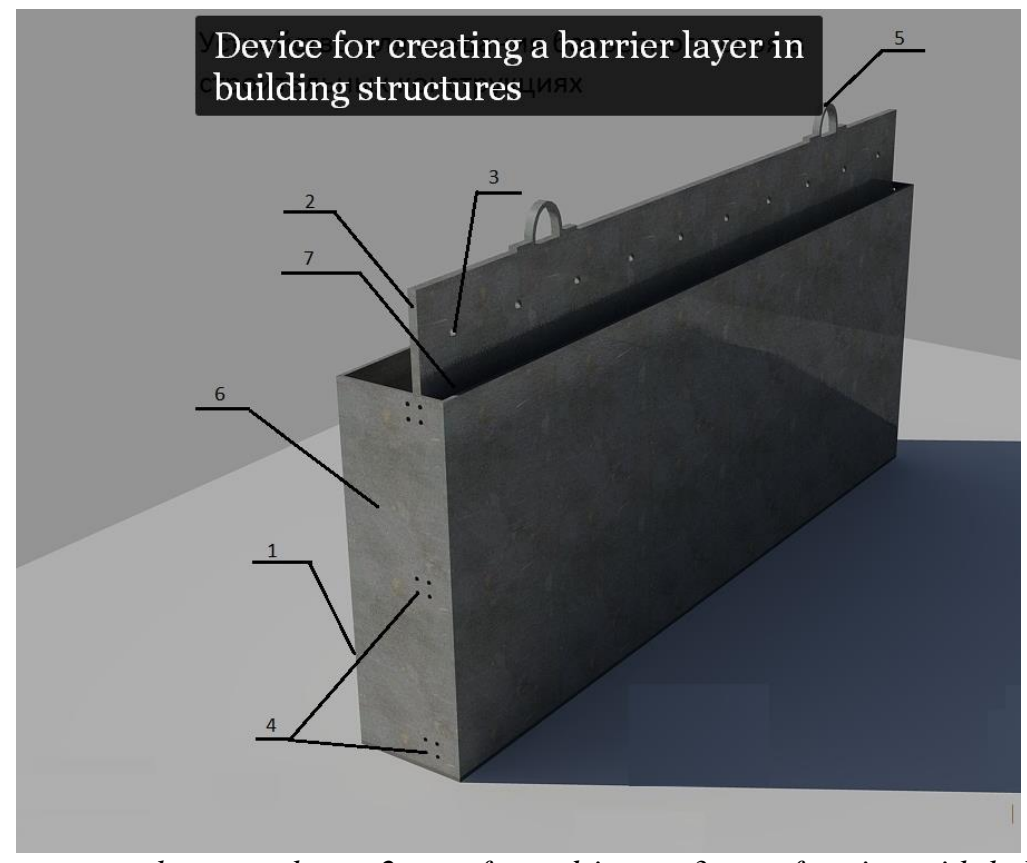

1 - rectangular type shape, 2 - perforated insert, 3 - perforation with holes $d=5 \mathrm{~mm}, 4$ - paired movable clips, 5 - mounting loops, 6 - end faces of the form, 7 - compartment separated by the insert.

Fig. 1. Device for creating a barrier layer in building structures

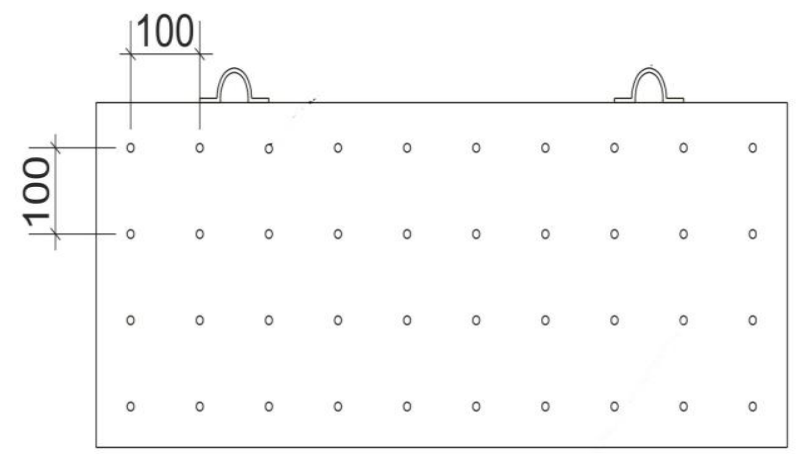

Fig. 2. Perforated metal liner 


\section{$2-3 \mathrm{~cm}$ from the edge of the form}

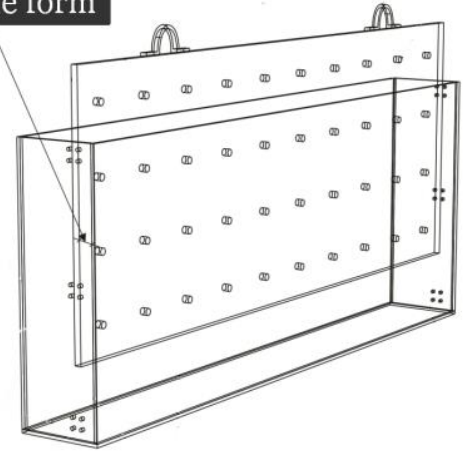

Fig. 3. Form scheme.

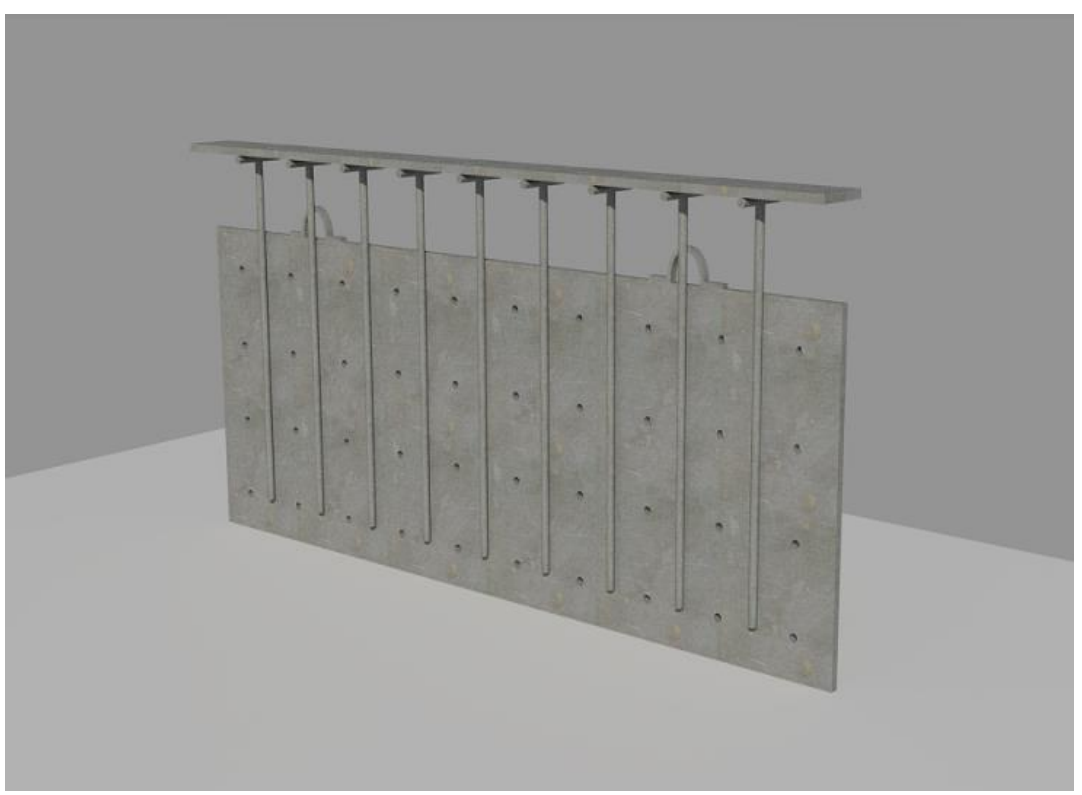

Fig. 4. General view of the liner-2 for transmission of vibration load 


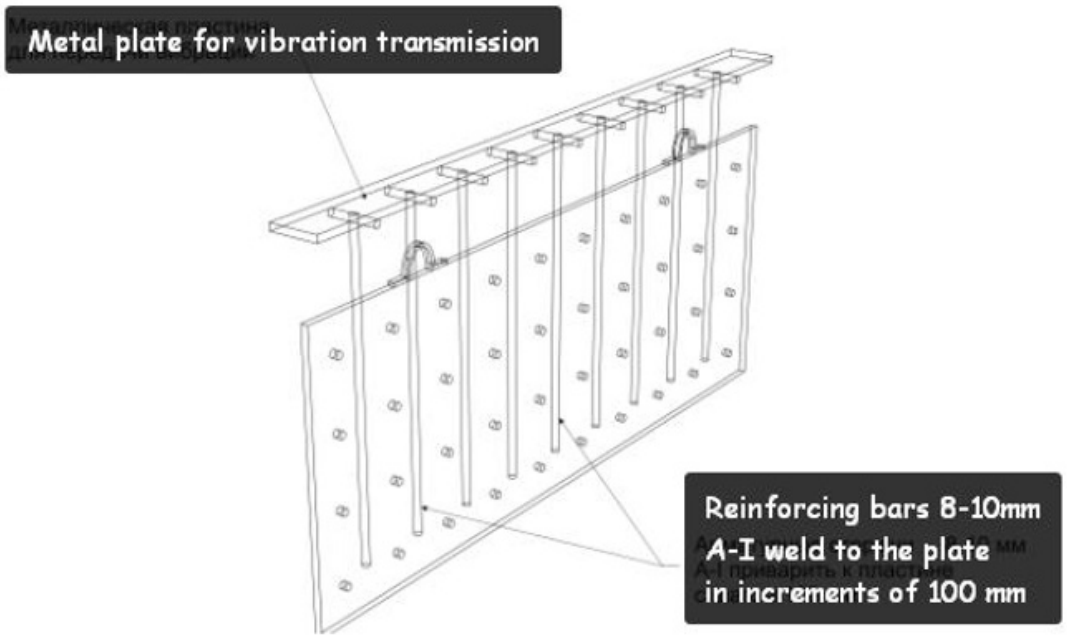

Fig. 5. Liner scheme

Materials with uneven grains with different mechanical composition will provide less resistance than materials with a finely dispersed structure. Considering that, such factors as capillary size, mechanical composition, and composition of absorbed substrates serve to increase the resistance of building materials and the effects of aggressive environments. It is recommended to use chipless concrete made of local, substandard sand with the addition of finely ground flasks as the material of the barrier layer.

The flasks are introduced into the composition of crushed stoneless concrete, and this is how it is worth characterizing the material obtained, since its use, as a sorbent material with unique ability to neutralize salts of heavy metals and their radionuclides is widely known.

Flasks - materials, natural aluminosilicates, have a set of properties that can solve various problems that arise during the operation of construction sites. Molecular ratio $\mathrm{SiO}_{2}$ : $\mathrm{R} 2 \mathrm{O} 3$ (sesquioxides), for flasks it is more than four and varies from 5.8 to 10 [8-10]. A similar molecular ratio is characteristic of clays and flasks of montmorillonite composition $[3,4]$.

\section{Results}

To evaluate the density of the material of the barrier layer, experimental series of plates with a size of $15 \times 15 \times 1.2(1.3) \mathrm{cm}$ were made:

- series No. 1 was made using local substandard sand and a mineral additive as inert material with a ratio of C/S/A as 1: 1.5: 0.2 (Table No. 1);

- Series No. 2 was made without the use of sand (table. No. 2).

Table 1. Series No. 1

\begin{tabular}{|c|c|c|c|c|}
\hline No. & $\begin{array}{c}\text { Ratio } \\
\text { C/S/A }\end{array}$ & $\begin{array}{c}\text { Sample weight } \\
\mathrm{kg}\end{array}$ & $\begin{array}{c}\text { Sample volume } \\
\mathrm{m}^{3}\end{array}$ & $\begin{array}{c}\text { Sample density } \\
\mathrm{kg} / \mathrm{m}^{3}\end{array}$ \\
\hline 1 & $1: 1,5: 0,2$ & 0,706 & 0,00025 & 2824 \\
\hline 2 & $1: 1,5: 0,2$ & 0,721 & 0,00027 & 2670 \\
\hline 3 & $1: 1,5: 0,2$ & 0,698 & 0,00025 & 2792 \\
\hline
\end{tabular}


Table 2. Series No. 2

\begin{tabular}{|c|c|c|c|c|}
\hline No. & $\begin{array}{c}\text { Ratio } \\
\text { C/A }\end{array}$ & $\begin{array}{c}\text { Sample weight } \\
\mathrm{kg}\end{array}$ & $\begin{array}{c}\text { Sample volume } \\
\mathrm{m}^{3}\end{array}$ & $\begin{array}{c}\text { Sample density } \\
\mathrm{kg} / \mathrm{m}^{3}\end{array}$ \\
\hline 1 & $1: 0,2$ & 0,594 & 0,00029 & 2048,3 \\
\hline 2 & $1: 0,2$ & 0,573 & 0,000288 & 1975,9 \\
\hline 3 & $1: 0,2$ & 0,609 & 0,000291 & 2100 \\
\hline
\end{tabular}

As for the heavy concrete, intended for laying in the main volume of the mold - this can be the composition of any grade in strength in accordance with the design decision. It should be noted that it is necessary to comply with the water-cement ratio for the two compositions.

The composition of the concrete mixture in the process of preparation is adjusted taking into account the particle size distribution of sand and coarse aggregate, their moisture content in the manufacture of the mixture to comply with a given water-cement ratio.

When laying concrete according to the "screen technology", it is necessary to control not only the formwork state but also the position of the metal inserts, their firm fixation in the formwork design, to prevent possible extrusion of the insert by concrete mix laid in the main volume of the mold.

The quality control of the concrete mixture must be carried out both in the preparation process and in the finished state. In the conditions of the construction site, it is necessary to control the mobility of the concrete mixture at least twice per shift with the preparation of relevant acts under stable weather conditions and every 2 hours under changing weather conditions.

It is necessary to establish constant monitoring of the compressive strength of concrete. It is necessary to carry out selective control with the preparation of acts. In the event of a discrepancy between the strength characteristics of the requirements of the design documentation, continuous control of the structure should be carried out with nondestructive methods.

The frost resistance and water tightness of concrete samples should be checked when designing the composition when changing the used aggregates and binders, but at least once a quarter.

\section{Conclusions}

Thus, as a result of the research, laboratory composite compositions with specified physical and technical characteristics were obtained. From the obtained experimental data, it follows that the introduction of a finely ground flask improves the absorbing and reflective properties of the modified composite, and increases the mass of the rubble-free composition. In the process of studying the identified problems and as part of the work on the topic, a device for creating a barrier layer was proposed and experimentally tested; an application for patenting a utility model was filed.

\section{References}

1. N. D. Sizova, I. A. Mikheev, East European journal of advanced technologies. 44, 8$10(2010)$.

2. A.V. Usherov-Marshak, T. V. Babaevskaya, Concrete and reinforced concrete 1, 5-7 (2002). 
3. N. M. Alykov, N. N. Alykov, T. V. Alikova et al., Gaizes of the Astrakhan region (Astrakhan, Publishing house "Astrakhan University", 2005).

4. Yu. G. Kozhevnikov et al., Geology, geography and global energy 4, 75-84 (2011).

5. Yu. G. Kozhevnikov, V. D. Bashmachnikov, Materials IX International scientificpractical conference (Astrakhan, publishing house of the Astrakhan state University, 2015).

6. Yu. G. Kozhevnikov, V. D. Bashmachnikov, D. A. Plotnikova, Science of Science 7(5) (2015).

7. A. O. Lukin, V. Y. Alpatov, Materials Science Forum 931, 247-251 (2018). DOI: 10.4028/www.scientific.net/MSF.931.247.

8. T. V. Lykova, S. N. Fedorova, I. V. Shatokhina, Ecological systems and devices 8, 12-16 (2005).

9. L. V. Pushkareva, O. A. Galochkina, O. L. Bezgacheva, Espacios 40(4), 22 (2019).

10. T. V. Alykova, N. M. Alikov, N. N. Alikov, N. And. Voronin, K. P. Pashchenko, Izv. Higher educational. Chemistry and chem. Technology 6, 31-34 (2003). 